\title{
SOCIAL WORK EDUCATION IN ALCOHOLISM
}

\author{
Charles Garvin \\ School of Social Work, University of Michlgan \\ Ann Arbor, Mich.
}

In considering what type of changes in the curricula of schools of social work will produce practitioners better trained in dealing with problems of alcoholism, a brief review of current social work activities in this area is pertinent. It is hard to find a social work agency without a significant number of problem drinkers among its clientele. Estimates, for example, have indicated that as high as 25 per cent of the caseloads of public assistance agencies may consist of families with alcoholics. Social workers in psychiatric hospitals are also extensively involved with this population as well as social workers in general hospitals, particularly those assigned to alcoholic wards.

Social workers in family agencies report that the marital problems with which they deal are often associated with the problematic use of alcohol by one or another of the adults in the family. Social workers in such correctional settings as prisons and reformatories also find that the inmates had made extensive use of alcohol or drugs. Social workers in protective services or in placement services for children also frequently indicate that alcoholism was associated with the deterioration or breakup of the home. Social workers in some of the manpower programs developed recently to retrain welfare populations or other low-income groups also encounter, as a frequent reason for poor participation in such programs, the alcoholism of one of the enrollees.

In addition to programs, such as the aforementioned, not specifically established to treat alcoholic populations but actually encountering this group extensively, social workers have been employed as a large proportion of the staffs of agencies established to deal with alcoholics. Among these agencies have been the local alcoholism clinics and alcoholic halfway houses. Social work schools also train practitioners of other social work specialities who must deal with the problems of alcoholism. Community organization practitioners, confronted with the lack of facilities in their communities or their coordination must struggle to deal with the problems of acquiring resources and legal authority to deal with problems of alcoholism. Social workers trained to fulfill social planning roles in city, state, and Federal governments also are called on to determine how to use their roles in relationship to allocation of resources and planning of programs. Finally, social work administrators in many types of agencies are confronted with the problem of training staffs and equipping them with the resources necessary to deal with the problems of alcoholism-problems that often are not recognized. When they are recognized, administrators must be concerned when the alcoholic label is sufficient to cause the client to be assigned the lowest priority for help.

The question is how staff members for all these programs are equipped by their professional education to deal with such a devastating array of human problems. A survey of offerings in all schools of social work has not been made, but one was conducted by this author regarding what is now being taught in one large and quite adequately staffed school. The situation in this school, used as an example, will then be reviewed and a plan for improvement noted. It is hoped that such a plan will suggest at least one useful model for improved professional education in this field.

In the school tu be described, no single course is totally devoted to the prob- 
lems of addiction. The students, however, in the clinical specialities of casework and group work are taught contemporary psychological theories of the causes of alcoholism in a general-survey course in psychopathology. They are also taught learning-theory approaches to the same topic in another required course that is concerned with the application of behavior modification to social work practice.

Other encounters with material on alcoholism, according to this survey, depended considerably on the interests and knowledge of the instructor or on the electives chosen by the student. Students who elect a course on medical information or on mental health programs do have units on resources for treatment of alcohol addiction. Students in methods courses in casework and group work may or may not examine cases of the treatment of alcoholics, depending on their or their instructors' interest preferences.

Students who select a course in the sociological analysis of deviance may examine such topics as the social determinants of alcoholic careers, subcultural factors in alcoholic deviance, and other predisposing forces toward alcoholism in the social environment. One other faculty member has been engaged in a study of the relationship of alcoholism to traffic accidents and to violence and has indicated that he has been introducing his findings into appropriate courses.

Despite the fact that social workers have been associated with community organization and social planning activities related to alcoholism, there was no indication of any concerted attention to this. Faculty have contended, however, that the course material is generic and can be adapted to working with problems of alcoholism as well as any other problems, and there is some truth in this assertion. Students majoring in these social work specializations, however, may be enrolled in the deviance course, the courses on mental health and medical resources, or the social problem-oriented course, all of which have some units on alcoholism.

In the academic year $1968-69$, one student was placed with a state representative who is chairman of a legislative committee on alcoholism and drug problems. The student helped to implement a plan that, it is hoped, will lead to the appropriation of more money for alcoholism programs and the initiation of a statewide drug abuse program. Another student worked with a statewide voluntary association in the field of alcoholism and drug addiction.

Part of the survey asked the faculty members whether their advisees [all faculty serve as advisers and field liaison personnel to some students] are in any way working with problems of alcoholism. Of the 36 faculty members who responded to the questionnaire, five indicated their students were working with alcoholics or on problems of alcoholism, 29 said their students were not, and two did not know. The students who were known to be working in the area of alcoholism were assigned to a Veterans Hospital, a community mental health program, a general hospital, a state mental hospital, a rehabilitation program, and an "outreach" program in a housing project. I believe, however, that many faculty members-like many students themselves-may not even know that their students are working on alcohol-related problems. Had time permitted, it would have been valuable to provide the students with a comprehensive questionnaire to determine whether they knew alcohol problems when they saw them, whether they were conscious of working on such problems, or even whether their clientele manifested problems that we might deduce were alcohol-related.

Depending on one's outlook this picture may appear either quite ample or quite limited. It is my contention in any case that there are several problems with 
the above-described curriculum in view of the kinds of tasks social workers are called on to perform in relationship to alcoholism and the immensity of the problem of alcoholism today. Some of these problems are as follows:

1. Students seeking a deeper exploration of alcoholism, with or without a consideration of other addictions, than that available in general-survey courses do not have such an option.

2. There are no field placements currently being utilized that focus largely or entirely upon alcoholism.

3. There is no information on whether faculty are presenting current material on alcoholism even when they are disposed to deal with the topic.

4. There is no integration among the theory, methods, and resources courses to ensure that major gaps do not exist in what the students learn about alcoholism, for students who determine to specialize in this problem, as well, of course, as for all students.

5. Perhaps the most telling critique of the entire program is that it is quite possible for students to complete their entire professional sequence with only a perfunctory review of theories of alcoholic behavior, and then only if they are specializing in casework or group work. True enough, some students may select the full range of offerings noted herein, but this rests too often upon the accidental selection of particular instructors, knowledgable in this area, or courses which are devoted in part to alcoholism. The implication of this, of course, is that while virtually all of the students will be required to deal with problems of alcoholism as one of the major problems occurring in almost all social welfare agencies, their education on this topic may be quite limited. It is no wonder that a pessimism characterizes so many social workers who are required to work with situations associated with alcoholism.

Another consideration is that, as a result of this type of circumstances in schools of social work, when a program is established to deal explicitly with alcoholism and a social worker is sought for a practitioner or administrative position it is extremely difficult to find a worker adequately prepared for this responsibility. It is true that some social workers avail themselves of the special institutes on this subject, but this should be viewed as a corrective for a lack that should not have existed in the first place.

The following is offered as a plan to resolve problems noted in the current curriculum. The first requirement of such a plan is the financing and recruitment of a faculty member whose major, if not exclusive, responsibility will be to perform a series of related tasks. First, the faculty member should be responsible for determining the curricular requirements necessary for two types of studentsthose who wish to specialize in work related to alcoholism and those who, while not specializing in this area, will need to be prepared for their inevitable encounters with this type of problem.

This individual will encounter a basic concern of any school of social work that has to do with the generic versus the specific nature of its content. In other terms, a decision must be made as to the degree to which basic aspects of social work training can be applied to work in alcoholism and the extent to which specific applications to alcoholism must be provided in the relevant courses in theory, methods, and services. The concern will be expressed and have to be dealt with that greater attention to problems of alcoholism must be weighed against greater attention to psychoses, criminality, disability, physical disease, and all the other social problems faced by social workers.

In dealing with this concern, the faculty member will have to determine what 
content is genuinely generic to alcoholism, what will facilitate the application social work students make of this content to work in alcoholism, and what specific content will then become necessary. The faculty member, to gain credibility with his colleagues, will also have to calculate the relative importance for training purposes of such social problems as those just enumerated-although he will certainly press the point of the degree to which problems of alcoholism are related to so many of these other conditions.

It may be that some compromises in this effort will have to be made. For example, one faculty member has suggested that a social-problems seminar might, by prescheduling, alternate problems of alcoholism as the subject matter of one entire semester with content related to other social problems in the other three semesters. When this course is a requirement the students could, however, select the course during the semester of their tenure when the problem area of greatest concern to them is presented.

Let us return to the curriculum to be developed for all students as well as students specializing in alcoholism. For all students, the faculty member providing leadership will first have to educate fellow faculty members in the most recent developments in this field. A problem here will be faculty motivation to acquire this material. One approach that has been used with some success is to provide all faculty members with some type of "test" of their knowledge on this topic and their ability to apply it. Faculty members who receive feedback indicating a lack of such knowledge can be motivated to attend some form of workshop or institute to acquire it.

Even with motivation, material for general use in social work classes on alcoholism is scarcely at hand, and its greater availability will be an important factor in its use. Social work educators are awaiting the publication of a sourcebook on alcoholism now being written by Herman Krimmel of Cleveland under the sponsorship of the Council on Social Work Education. The faculty member posited here, however, will have to develop additional materials, as they are needed, for local circumstances.

Another important task for the faculty member will be to convene such faculty task groups as are necessary to promote integration of the offerings of the school related to alcoholism. This should also be aided by additional efforts to secure feedback from students regarding gaps in their knowledge and difficulties they are encountering in identifying and working with alcoholism problems.

Additional efforts will be required of the faculty member for students who request a greater degree of concentration on this topic. In the first place, there should be at least one regularly offered course with alcoholism as its major topic. This course should enable the students to apply materials learned in psychopathology and personal and social psychology to the condition of alcoholism. The course, or perhaps courses, should also consider the community organization and administrative and social policy implications of the prevention and treatment of alcoholism.

A second major resource for the training of students who desire to specialize in this area must be the further development of field placements. Obstacles to the utilization of social work students in the settings entirely devoted to alcoholism or alcoholism and drug addiction must be overcome. These obstacles have to do with the availability of supervisory personnel, the readiness of the agency to work with students, and the diversity of experience that is made available to the students. Another dimension of the development of field placements is the placement of students into other types of settings with a special emphasis on work 
with alcoholics in these settings. This is desirable only if adequate consultation is available.

One other problem must be solved before students can be adequately trained in work with alcoholism in these secondary settings. This is the issue of the degree to which it is desirable or feasible to treat specified categories of alcoholics in such social work settings as family or child welfare agencies as well as in the organizations devoted exclusively to addiction problems. It is certainly true that many workers in these settings believe that all recognized alcoholics must be referred, and a review of this issue will form a basis for decisions on the placement question.

Finally, the program of more specialized training must provide an opportunity for the students and faculty in the program to work effectively together. A major consideration for this working together is feedback leading to the development of the program as approaches are tested and new ideas emerge.

The school being utilized as an example here has determined through a recent grant application that it wishes to develop a particular emphasis for training community, policy, and administrative personnel in alcoholism. In its proposal, this was justified as follows:

Despite an already considerable and growing body of knowledge which deals with addressing social problems at the community and societal level, attention to problem-solving is thus occurring at a level disproportionate to the size of the problem and in ways which cannot hope to do more than relieve small numbers of the people affected. Development and specification of new professional roles vis-à-vis alcoholism, together with expanded training of social workers adequately prepared to fulfill these more demanding roles, is necessary if discernible progress is to be made in meeting with the problem in its present dimensions.

This will be implemented in this manner:

Providing or facilitating field instruction for students enrolled in the community practice, administration, and policy methods specializations of the School engaged in activities related to alcoholism. Although the request is for funds to provide stipends for six students, efforts will be made to extend relevant field instruction for as many students as possible. It is anticipated that the faculty member initially will need to engage himself directly in the field instruction activities, thus limiting the number of students to whom he can give direct field instruction. As the school graduates students who are employed in alcoholismrelated programs, and as other persons with competence as field instructors become available through the School's continuing education activities or other means, responsibility for field instruction can be gradually transferred to the agencies in which the students are placed. It will become increasingly possible for the project faculty to deal with matters of program and field site development, consultation concerning policy and program changes in a variety of settings, and similar activities. From the inception of the project, the faculty person recruited should find it possible to relate to the mental health project mentioned earlier and thus involve himself in the training concerns of a large number of students with a career commitment in mental health. The Department of Public Health Alcoholism Program and the Alcohol and Addiction Association are state-wide programs that have expressed an 
interest in training students. Some interest has also been expressed by a number of other locally-based alcoholism programs.

In conclusion, I would like to state my conviction of the importance of the kind of dialogue initiated at this conference. We may have missed some past opportunities, but, with this kind of thinking, we shall not miss future ones. 